\title{
Perspektywy budowy parku przemysłowo- technologicznego dla mieszkańców Zagłębia Miedziowego \\ Grzegorz PRZYBYLSKI
}

${ }^{1)}$ KGHM Polska Miedź S.A., Uniwersytet Ekonomiczny we Wrocławiu; email: grzegorz.przybylski@kghm.com

http://doi.org/10.29227/IM-2020-01-22

Submission date: 04-12-2019 | Review date: 16-02-2020

\section{Abstrakt}

W artykule przedstawiono perspektywy budowy parku przemysłowo-technologicznego zlokalizowanego na terenie gminy miejskiej oraz wiejskiej Lubin. Obszar ten charakteryzuje się monokultura przemystu miedziowego związanego z największym pracodawca w regionie - KGHM Polska Miedź S.A. Działalność wydobywcza Polskiej Miedzi w perspektywie długookresowej będzie ograniczana. $Z$ tego względu szuka się innych możliwości wykorzystania potencjału regionu. Wydaje się, że jednym z najbardziej obiecujących jest budowa parku przemysłowo-technologicznego. Zainteresowanie tym przedsięwzięciem okazują samorzady (lokalne samorządy, Województwo Dolnoślaskie), Agencja Rozwoju Przemysłu, Krajowy Ośrodek Wsparcia Rolnictwa, przedstawiciele firmy KGHM Polska Miedź S. A. oraz przedstawiciele Kancelarii Prezesa Rady Ministrów.

Słowa kluczowe: Lubin, park przemysłowo-technologiczny, KGHM Polska Miedź S. A., LGOM

Historia Zagłębia Miedziowego rozpoczyna się odkryciem w 1957 roku bogatych złóż miedzi, co dało podstawę rozwoju Legnicko-Głogowskiemu Okręgowi Miedziowemu. W kolejnych latach powstawały kopalnie Lubin, Polkowice, Sieroszowice i Rudna, a także huty miedzi w Głogowie i Orsku, zmodernizowano również hutę $\mathrm{w}$ Legnicy. Na potrzeby związane z przemysłem miedziowym, powstawały nowoczesne zakłady produkcyjne i usługowe. Dziś Zagłębie Miedziowe jest zagłębiem innowacji[1]. Od tego wydarzenia upłynęly 63 lata. Od paru lat samorządowcy z Lubina, co jakiś czas poruszają temat budowy parku przemysłowo-technologicznego. $\mathrm{W}$ ostatnim roku, kiedy podpisano porozumienie dotyczące utworzenia parku przemysłowo-technologicznego w niedalekiej przyszłości taka inwestycja może stać się faktem.

Polska Agencja Rozwoju Przedsiębiorczości (PARP) na podstawie ustawy z dnia 29 sierpnia 2003 r. o zmianie ustawy i finansowym wspieraniu inwestycji oraz ustawy o warunkach dopuszczalności i nadzorowaniu pomocy publicznej dla przedsiębiorców definiuje park technologiczny jako: „zespół wyodrębnionych nieruchomości wraz z infrastrukturą znajdującą się na nich, utworzony w celu dokonywania przepływu wiedzy i technologii pomiędzy jednostkami naukowymi a przedsiębiorcami. Na terenie parku technologicznego oferowane są przedsiębiorcom wykorzystującym nowoczesne technologie usługi $\mathrm{w}$ zakresie doradztwa $\mathrm{w}$ tworzeniu i rozwoju firmy, transferu technologii i przekształcanie wyników prac badawczych w innowacje technologiczne. Park umożliwia także przedsiębiorcom korzystanie z nieruchomości i infrastruktury technicznej na zasadach umownych. Podstawowym elementem działalności parku technologicznego jest zapewnienie warunków umożliwiających ścisłą współpracę między lokalnymi ośrodkami naukowymi a przedsiębiorstwami zorientowanymi innowacyjnie." oraz park przemysłowy w następujący sposób „zespół wyodrębnionych nieruchomości wraz z infrastrukturą techniczną, umożliwiający prowadzenie działalności gospodarczej na preferencyjnych warunkach. Polskie parki przemysłowe mają przede wszystkim przyciągać inwestorów tworzących nowe miejsca pracy, co przyczynić się ma do amortyzacji skutków restrukturyzacji przemysłu”[2].

Park przemysłowo-technologiczny został zdefiniowany przez Polską Agencję Inwestycji i Handlu Grupa PFR jako „zespół wyodrębnionych nieruchomości wraz ze znajdującą się na nich infrastrukturą pozostałą po restrukturyzowanych lub likwidowanych przedsiębiorstwach oraz inne dołączone do nich nieruchomości. Tego typu parki tworzone są przy udziale władz samorządowych w celu zapewnienia preferencyjnych warunków prowadzenia działalności gospodarczej, w szczególności dla małych i średnich przedsiębiorstw. Cele wyznaczane parkom przemysłowo-technologicznym to przede wszystkim:

- zapełnienie oferowanej powierzchni rynkowo skutecznymi firmami wykorzystującymi nowoczesne technologie,

- przyciąganie inwestorów,

- $\quad$ tworzenie miejsc pracy[3]."

W Polsce funkcjonuje obecnie 80 parków w różnych formach prawnych: parki przemysłowe, technologiczne, naukowo-technologiczne, agro-przemysłowe oraz parki przemysłowo-technologiczne. Najwięcej jak pokazano na poniższej mapce stworzonej przez Polską Agencję Inwestycji i Handlu znajduje się w mocno uprzemysłowionym województwie śląskim - 4 parki, co wskazuje na to, że jest to alternatywa dla występującego w tamtym regionie przemysłu wydobywczego.

Poniższa tabela wymienia parki przemysłowe, parki technologiczne (czcionka pogrubiona), parki przemysłowo-technologiczne oraz parki agro-przemysłowe.

Legnicko Głogowski Okręg Miedziowy („LGOM”) to obszar przemysłowy w województwie dolnośląskim o powierzchni $2735,87 \mathrm{~km}^{2}$ i populacji około 0,5 mln mieszkań- 


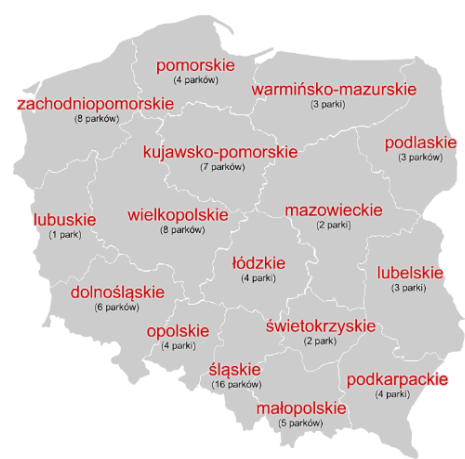

Rys. 1. Mapa Polski: parki przemysłowe, parki technologıczne, parkı przemysłowo-tecnnologıczne agro-przemysłowe [Źródło: https//www.paih.gov.pl] Fig. 1. Map of Poland: Industrial parks, technological parks, industrial and technological parks, agro and industrial parks [Source: https://www.paih.gov.pl]

ców, zlokalizowany na terenie powiatów: legnickiego, lubińskiego, polkowickiego oraz głogowskiego.

Na podstawie odległości ze strony Google Maps w poniższej tabeli pokazano alfabetycznie odległości Lubina od innych miast, granicy z Czechami i Niemcami oraz odległości do portów morskich. W tabeli pokazano również odległość między Lubinem a ośrodkami akademickimi (uczelnie techniczne) takimi jak Kraków (Akademia Górniczo-Hutnicza), Poznań (Politechnika Poznańska), Wrocław (Politechnika Wrocławska).

W rankingu dochodów JST 2018 „Bogactwo samorządów” stworzonego przez pismo „Wspólnota” poświęcone samorządom przedstawiono zamożność miast per capita w Polsce za lata 2010-2018. Bardzo wysokie miejsca zajmują miasta związane z Legnicko-Głogowskim Okręgiem Miedziowym: Polkowice 1, Lubin 16, Głogów 22 na 267 „miast powiatowych” oraz Legnica 29 na 144 miasta na prawach powiatu wśród miast ujętych $w$ rankingu.

Grupa kapitałowa KGHM Polska Miedź S.A. jest globalną oraz innowacyjną organizacją, która prowadzi działalność $\mathrm{w}$ takich obszarach jak górnictwo, hutnictwo oraz przeróbka. KGHM należy do ścisłej czołówki producentów srebra i miedzi. Zlokalizowana jest w zachodniej części województwa dolnośląskiego wraz z Grupą Kapitałową KGHM zatrudnia około 32 tysiące osób. Oddziały firmy: kopalnie, huty miedzi, zakłady wzbogacania rud oraz Zakład Hydrotechniczny znajdują się w regionie Legnicko Głogowskiego Okręgu Miedziowego. KGHM prowadzi działalność na czterech kontynentach: w Europie, Ameryce Południowej, Ameryce Północnej oraz Azji. Grupę Kapitałową KGHM Polska Miedź S. A. tworzy KGHM Polska Miedź S.A. jako jednostka dominująca oraz kilkadziesiąt spółek zależnych - w sumie 75 podmiotów, zatrudniając 34 tysiące pracowników[4]

Poniższy rysunek pokazuje lokalizację aktywów związanych z działalnością Grupy Kapitałowej KGHM Polska Miedź S.A. w Polsce:

W ostatnich latach pojawiło się wiele informacji na temat budowy parku przemysłowo-technologicznego. W prasie pojawiły się różne pomysły na zagospodarowanie tego terenu. Dziś w przestrzeni informacyjnej funkcjonuje jako park przemysłowo-technologiczny oraz Strefa Przemysłowa S3 (droga S3 przebiega przez tereny przeznaczone pod inwestycje). Teren parku to około 400 hektarów podzielonych na cztery części: kompleks A (139,86 ha), kompleks B (13,31 ha), kompleks C (26,31), kompleks D (213,30 ha). Na 2020 rok plano- wana jest również budowa obwodnicy miejscowości Krzeczyn Wielki usytuowanej bezpośrednio przy terenach planowanych pod inwestycje. Na poniższym wizualizacji stworzonej przez Urząd Gminy Lubin zaznaczone są: obszary Parku (A, B, C, D), położenie miasta Lubin, droga S3 (łączącą Legnicę z Zieloną Górą), droga 335 w kierunku Zgorzelca przez miejscowość Chojnów oraz żółtym kolorem planowana obwodnica Krzeczyna Wielkiego.

W przyszłości wraz z kończącymi się pokładami miedzi sytuacja może doprowadzić do znacznej redukcji zatrudnienia oraz w dalszej perspektywie zamknięcia poszczególnych Oddziałów. Mając na uwadze powyższe prowadzi się analizy możliwości utworzenia parku przemysłowo-technologicznego na obszarze LGOM.

Dnia 17 października 2018 roku w siedzibie firmy KGHM Polska Miedź S.A. podpisano trójstronną umowę o utworzeniu parku przemysłowo-technologicznego zlokalizowanego przy trasie S3 w miejscowości Krzeczyn Wielki oraz mieście Lubin. Sygnatariuszami są Krajowy Ośrodek Wsparcia Rolnictwa, Agencja Rozwoju Przemysłu i KGHM Polska Miedź S.A. W ramach podpisanej umowy Krajowy Ośrodek Wsparcia Rolnictwa przekaże Agencji Rozwoju Przemysłu 400 hektarów gruntów. Operatorem Parku będzie Agencja Rozwoju Przemysłu.

W planach związanych z parkiem jest zlokalizowanie firm produkcyjnych $z$ takich branż jak: zielona energetyka, innowacyjny przemysł rolniczy i maszynowy. W projekt chce się zaangażować KGHM Polska Miedź S. A., który bezpośrednio nie będzie zajmować się tworzeniem parku. Firma zamierza przekonywać swoich kooperantów do inwestowania na tym obszarze[5].

Na kolejnym spotkaniu, które odbyło się dnia 27 maja 2019 w Kancelarii Prezesa Rady Ministrów poruszono temat komercjalizacji „Strefy Przemysłowej S3” (park przemysłowo-technologiczny) w spotkaniu uczestniczyli przedstawiciele samorządu, samorządu województwa dolnośląskiego, Krajowego Ośrodka Wsparcia Rolnictwa, Agencji Rozwoju Przemysłu, przedstawiciele Prezesa Rady Ministrów. Jednym $\mathrm{z}$ tematów było utworzenie centrum badawczo-rozwojowego wraz z inkubatorem przedsiębiorczości, w skład którego mogłyby wejść Agencja Rozwoju Przemysłu, KGHM Polska Miedź S.A. oraz samorząd województwa dolnośląskiego. Pozwoli to na wprowadzenie nowych rozwiązań na bazie miedzi, która jest wykorzystywana m. in. w medycynie, energetyce czy fotowoltaice. Rozmawiano również o rozbudowie infrastruk- 
Rys. 1. Mapa Polski: parki przemysłowe, parki technologiczne, parki przemysłowo-technologiczne agro-przemysłowe [Źródło: https//www.paih.gov.pl] Fig. 1. Map of Poland: Industrial parks, technological parks, industrial and technological parks, agro and industrial parks [Source: https://www.paih.gov.pl]

\begin{tabular}{|c|c|c|}
\hline Województwo & $\begin{array}{l}\text { Liczba } \\
\text { Parków }\end{array}$ & Nazwa Parku \\
\hline dolnośląskie & 6 & $\begin{array}{l}\text { - Dolnośląski Park Technologiczny } \\
\text { - Legnicki Park Technologiczny Letia S.A. w Legnicy } \\
\text { - Noworudzki Park Przemysłowy } \\
\text { - Park Przemysłowy Bukowice } \\
\text { - Wrocławski Park Przemysłowy } \\
\text { - Wrocławski Park Technologiczny S.A }\end{array}$ \\
\hline $\begin{array}{l}\text { kujawsko- } \\
\text { pomorskie }\end{array}$ & 7 & $\begin{array}{l}\text { - Bydgoski Park Przemyslowo-Technologiczny } \\
\text { - Grudziądzki Park Przemysłowy } \\
\text { - Park Przemysłowy w Solcu Kujawskim } \\
\text { - Płużnicki Park Inwestycyjny } \\
\text { - Toruński Park Technologiczny } \\
\text { - Vistula Park } \\
\text { - Włocławska Strefa Rozwoju Gospodarczego - Park Przemyslowo- } \\
\text { Technologiczny }\end{array}$ \\
\hline lubelskie & 3 & $\begin{array}{l}\text { - Lubelski Park Naukowo-Technologiczny } \\
\text { - Puławski Park Naukowo-Technologiczny } \\
\text { - Puławski Park Przemysłowy }\end{array}$ \\
\hline lubuskie & 1 & - Lubuski Park Przemyslowo-Technologiczny \\
\hline łódzkie & 4 & $\begin{array}{l}\text { - Bełchatowsko Kleszczowski Park Przemysłowo-Technologiczny } \\
\text { - Bionanopark } \\
\text { - Kutnowski Park Agro-Przemysłowy } \\
\text { - Park Przemysłowy Boruta Zgierz } \\
\end{array}$ \\
\hline małopolskie & 5 & $\begin{array}{l}\text { - Krakowski Park Technologiczny } \\
\text { - MMC Brainville } \\
\text { - Park Lifescience Kraków } \\
\text { - Sosnowiecki Park Naukowo-Technologiczny } \\
\text { - Zielony Park Przemysłowy w Tarnowie }\end{array}$ \\
\hline mazowieckie & 2 & $\begin{array}{l}\text { - Park Naukowo-Technologiczny „Świerk” } \\
\text { - Plocki Park Przemysłowo-Technologiczny }\end{array}$ \\
\hline opolskie & 4 & $\begin{array}{l}\text { - Kędzierzyńsko-Kozielski Park Przemysłowy } \\
\text { - Opolski Park Naukowo-Technologiczny } \\
\text { - Park Naukowo-Technologiczny w Opolu Sp. z o.o. } \\
\text { - Park Naukowo-Technologiczny Branice }\end{array}$ \\
\hline podkarpackie & 4 & $\begin{array}{l}\text { - Mielecki Park Przemysłowy } \\
\text { - Park Przemysłowy Gminy Leżajsk } \\
\text { - Podkarpacki Park Naukowo-Technologiczny AEROPOLIS } \\
\text { - Tarnobrzeski Park Przemysłowo-Technologiczny }\end{array}$ \\
\hline podlaskie & 3 & $\begin{array}{l}\text { - Białostocki Park Naukowo-Technologiczny } \\
\text { - Park Naukowo-Technologiczny Polska-Wschód w Suwałkach }\end{array}$ \\
\hline pomorskie & 4 & $\begin{array}{l}\text { - Gdański Park Naukowo - Technologiczny } \\
\text { - Kwidzyński Park Przemyslowo - Technologiczny } \\
\text { - Pomorski Park Naukowo - Technologiczny Gdynia } \\
\text { - Słupski Inkubator Technologiczny }\end{array}$ \\
\hline śląskie & 16 & $\begin{array}{l}\text { - AURO Business Park Gliwice } \\
\text { - Bielski Park Technologiczny Lotnictwa, Przedsiębiorczości i Innowacji } \\
\text { - Bytomski Park Przemysłowy } \\
\text { - Częstochowski Park Przemyslowo-Technologiczny } \\
\text { - Euro-Centrum Park Naukowo-Technologiczny } \\
\text { - Euro-Centrum Park Przemysłowy } \\
\text { - Górnośląski Park Przemysłowy } \\
\text { - IT LOFT Park w Tychach } \\
\text { - Park Naukowo - Technologiczny "Technopark Gliwice" } \\
\text { - Park Przemyslowo-Technologiczny "Ekopark" } \\
\text { w Piekarach Śląskich } \\
\text { - Rudzki Inkubator Przedsiębiorczości } \\
\text { - Synergy Park } \\
\text { - Śląski Inkubator Przedsiębiorczości } \\
\text { - Śląski Park Przemyslowo-Technologiczny } \\
\text { - Zawierciański Park Przemyslowo-Technologiczny } \\
\text { - Żorski Park Przemysłowy }\end{array}$ \\
\hline świętokrzyskie & 2 & $\begin{array}{l}\text { - Kielecki Park Technologiczny } \\
\text { - Regionalne Centrum Naukowo-Technologiczne }\end{array}$ \\
\hline $\begin{array}{l}\text { warmińsko- } \\
\text { mazurskie }\end{array}$ & 3 & $\begin{array}{l}\text { - Elbląski Park Technologiczny } \\
\text { - Olsztyński Park Naukowo-Technologiczny } \\
\text { - Park Naukowo-Technologiczny w Ełku }\end{array}$ \\
\hline
\end{tabular}




\begin{tabular}{|c|c|c|}
\hline wielkopolskie & 8 & $\begin{array}{l}\text { - Eureka Technology Park } \\
\text { - Kaliski Inkubator Przedsiębiorczości } \\
\text { - Park Przemysłowy LUVENA Sp. z o.o. } \\
\text { - Poznański Park Naukowo-Technologiczny Fundacji Uniwersytetu } \\
\text { im. A. Mickiewicza } \\
\text { - Poznański Park Technologiczno-Przemysłowy } \\
\text { - Śremski Park Inwestycyjny } \\
\text { - Turecki Inkubator Przedsiębiorczości } \\
\text { - YouNick Technology Park }\end{array}$ \\
\hline zachodniopomorskie & 8 & $\begin{array}{l}\text { - Bałogardzki Park Inwestycyjny INVEST-PARK } \\
\text { - Goleniowski Park Przemysłowy } \\
\text { - Park Naukowo-Technologiczny Politechniki Koszalińskiej } \\
\text { - Park Przemysłowy Nowoczesnych Technologii w Stargardzie } \\
\text { - Park Regionalny w Gryfinie } \\
\text { - Stargardzki Park Przemysłowy } \\
\text { - Szczeciński Park Przemysłowy } \\
\text { - Technopark Pomerania }\end{array}$ \\
\hline
\end{tabular}

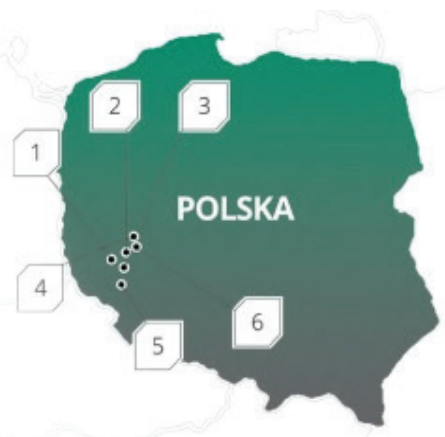

1. ZG Polkowice-Sieroszowice 2. ZG Rudna

3. ZG Lubin 4. HM Głogów 5. HM Legnica

6. HM Cedynia

Rys. 2. Lokalizacja aktywów Grupy Kapitałowej KGHM Polska Miedź S.A. [Źródło: Raport zrównoważony KGHM 2018, https://www.kghm.com] Fig. 2. Location of assets KGHM Capital Group [Source: Sustainable Annual Report 2018, https://www.kghm.com]

tury kolejowej związanej z powstającym parkiem, wybudowaniem drugiego zelektryfikowanego toru na linii nr 289 Legnica - Rudna Gwizdanów oraz nowego połączenia kolejowego Lubin - Polkowice - Głogów[6].

Tereny inwestycyjne przewidziane pod budowę parku przemysłowo-technologicznego zlokalizowane są w obszarze miasta Lubin oraz gminy wiejskiej Lubin, między miejscowością Obora, a miejscowością Krzeczyn Wielki. Obszar podzielony jest na 4 części, które przecina droga ekspresowa S3 łącząca Morze Bałtyckie z Czechami oraz droga wojewódzka nr 335. Na atrakcyjność położenia parku może też wpłynąć bliska odległość od autostrady A4 łączącej Niemcy z Ukrainą (około $30 \mathrm{~km}$ trasa Krzeczyn Wielki - autostrada A4). W planach jest również budowa obwodnicy Krzeczyna Wielkiego o długości 2,5 kilometra, która umożliwi bezpośredni wjazd do parku. Planowane rozpoczęcie oraz zakończenie inwestycji to 2020 rok.

Na terenie Lubina znajduje się sportowe lotnisko Aeorklubu Zagłębia Miedziowego z utwardzonym pasem startowym oraz radiolatarnią, przeznaczone jest dla samolotów sportowych oraz małych samolotów pasażerskich.

Park przemysłowo-technologiczny byłby pierwszym w województwie dolnośląskim. Lokalizacja Parku na terenie Zagłębia Miedziowego pozwoli stworzyć miejsca pracy poza przemysłem miedziowym oraz pozwoli osiągnąć następujące korzyści:

- $\quad$ stworzenie warunków do wykorzystania naukowego oraz przemysłowego potencjału regionu,
- stworzenie i rozwój regionalnej infrastruktury przemysłowej,

- podniesienie potencjału (konkurencyjności) regionu w sferze innowacji poprzez wzmocnienie współpracy pomiędzy sektorem badawczo-rozwojowym a gospodarką,

- przyciąganie nowych inwestorów z różnych gałęzi gospodarki,

- rozwój nowych technologii,

- wykorzystanie infrastruktury regionu po działalności związanej z KGHM Polska Miedź S. A.,

- powstanie nowych kierunków studiów,

- powstanie klas profilowych szkołach,

- powstanie inkubatora przedsiębiorczości lub/i klastra.

Z powyżej wymienionych zalet budowy parku wynika, iż stworzenie warunków pod taką inwestycje przyniesie szereg korzyści zarówno dla biznesu jak i dla społeczeństwa. Dzięki ulokowaniu na tym terenie firm $\mathrm{z}$ branż związanych $\mathrm{z}$ zieloną energią, produkcją wyrobów na bazie miedzi przyczyni się do powstania nowych kierunków na uczelniach oraz klas profilowych w szkoła średnich. Obecność KGHM-u w regionie powinna pomóc ściągnąć inwestorów z różnych gałęzi gospodarki, a potencjalny inkubator przedsiębiorczości lub klaster energetyczno-miedziowy pozwoli na współpracę, przenikanie się biznesu, nauki oraz samorządu lokalnego oraz wojewódzkiego. KGHM Polska Miedź S.A. jest członkiem Zgorzeleckiego Klastra Rozwoju Odnawialnych Źródeł 
Tab. 2. Odległości Lubina od granicy z Niemcami, Czechami, innych miast oraz portów

Tab. 2. Distance from Lubin from the border with Germany and the Czech Republic, other cities and ports

\begin{tabular}{|l|l|}
\hline Odległość od miasta Lubin (w km) & 280 \\
\hline Berlin & 360 \\
\hline Kraków & 26 \\
\hline Legnica & 160 \\
\hline Poznań & 220 \\
\hline Praga & 430 \\
\hline Warszawa & 69 \\
\hline Wrocław & 87 \\
\hline Zielona Góra & \\
\hline Odległość miasta Lubin do granicy (w km) & 115 \\
\hline Czechy (przejście w Jakuszycach) & 111 \\
\hline Niemcy (przejście w Zgorzelcu) & \\
\hline Odległość miasta Lubin od portów morskich (w km) & 300 \\
\hline Szczecin & 380 \\
\hline Świnoujście & \multicolumn{2}{|l}{} \\
\hline
\end{tabular}

Tab. 3. Zamożność miast w Polsce, Bogactwo samorządów Ranking dochodów JST 2018 [Źródło: Ranking dochodów JST 2018, www.wspolnota.org.pl] Tab. 3. The wealth of cities in Poland, Wealth of local governments JST 2018 revenue ranking [Source: Income Ranking JST 2018, www.wsspolnota.org.pl]

\begin{tabular}{|c|c|c|c|c|c|c|c|c|c|c|}
\hline 2010 & 2011 & 2012 & 2013 & 2014 & 2015 & 2016 & 2017 & 2018 & Miasto & $\begin{array}{c}\text { Zamożnó́ć per } \\
\text { capita 2018 (w zf) }\end{array}$ \\
\hline 1 & 1 & 1 & 1 & 1 & 1 & 1 & 1 & $\mathbf{1}$ & Polkowice & 6950,52 \\
\hline 20 & 21 & 4 & 6 & 8 & 9 & 14 & 15 & $\mathbf{1 6}$ & Lubin & 4006,24 \\
\hline 22 & 20 & 9 & 22 & 28 & 23 & 24 & 23 & $\mathbf{2 2}$ & Głogów & 3759,36 \\
\hline 30 & 32 & 28 & 27 & 30 & 25 & 33 & 30 & $\mathbf{2 9}$ & $\begin{array}{c}\text { Legnica }- \\
\text { miasto na } \\
\text { prawach } \\
\text { powiatu }\end{array}$ & 4190,30 \\
\hline
\end{tabular}

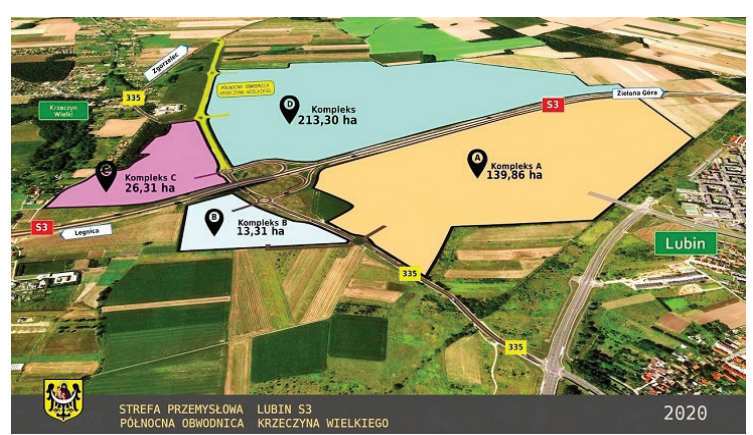

Rys. 3. Strefa Przemysłowa Lubin S3 oraz Północna Obwodnica Krzeczyna Wielkiego [Źródło: https://www.lubin.pl]

Fig. 3. Industrial Zone Lubin S3 and North Bypass of Krzeczyn Wielki [Source: https://www.lubin.pl]

Energii i Efektywności Energetycznej, którego celem są prace nad efektywnym wykorzystaniem lokalnych zasobów energetycznych w odnawialnych źródłach energii[7]. Wraz z powołaniem klastra związanego z głównym biznesem KGHM - produkcją związaną z miedzią, powstaną bardzo dobre warunki dla specjalistów z branż związanych z tym obszarem. Miedź może odegrać kluczowa rolę w procesie transformacji energetycznej. Warto przeanalizować, w jaki sposób można wykorzystać szanse związane z OZE na dużą skalę, pomyśleć, czy zamiast naśladować inne gospodarki, czy nie poszukać niszy rynkowych, w których „lokatorzy parku” będą prekursorami. Polityka dekarbonizacyjna i trendy światowe związane $\mathrm{z}$ rozwojem OZE, magazynowaniem energii czy elektromobilnością nie pozostawią nam innego wyjścia. Rocznie na świecie na rynek trafia około $23 \mathrm{mln}$ ton nowej miedzi, nie licząc recyklingu[8]. Miedź dominuje w produkcji kabli układanych na dnie morza bądź w systemach odgromowych i uziemień elektrowni wiatrowych. Miedzi nie da się zastąpić w konstrukcji toru prądowego (taśmy modułowe, przewody) paneli fotowoltaicznych. Coraz częściej wykorzystywana jest również w mikroprocesorach i układach chłodzenia komputerów[9]. Lokowanie przedsiębiorstw z wymienionych obszarów gospodarki pozwoli przyciągnąć inwestorów z różnych gałęzi gospodarki, podnieść konkurencyjność regionu i pozwoli rozpocząć współpracę sektora badawczo-rozwojowego (uczelnie, instytuty) z gospodarką.

W przyszłości będzie można wykorzystać pozostałości po likwidowanych zakładach np. hale produkcyjne, biurowce do rozbudowy park przemysłowo-technologicznego i ulokować na tych terenach nowe przedsięwzięcia. Już dziś Województwo Dolnośląskie wraz z lokalnymi samorządami rozwijają komunikację z regionem poprzez tworzenie nowych dróg, obwodnic oraz rozwojem połączeń kolejowych. Atrakcyjności lokalizacji inwestycji w tym miejscu dodaje również Dolno- 
śląski Klaster Lotniczy w Legnickiej Specjalnej Strefie Ekonomicznej zlokalizowany w Lubinie [10].

\section{Podsumowanie}

W niniejszym artykule przedstawiono krótką charakterystykę Legnicko-Głogowskiego Okręgu Miedziowego pod kątem potencjalnej budowy parku przemysłowo-technologicznego. Jest to jeden ze scenariuszy rozwoju gospodarczego północnych obszarów województwa dolnośląskiego. Prace związane $\mathrm{z}$ budową parku zostały już rozpoczęte - w dniu 17.10.2018 r. przedstawiciele agencji państwowych (Krajowy Ośrodek Wsparcia Rolnictwa, Agencja Rozwoju Przemysłu) oraz największy pracodawca w regionie, KGHM Polska Miedź S.A., zawarły umowę o utworzeniu parku przemysłowo-technologicznego zlokalizowanego przy trasie S3 w miejscowości Krzeczyn Wielki oraz mieście Lubin.

Perspektywa tego przedsięwzięcia może zapewnić wykorzystanie infrastruktury i zasobów ludzkich w przypadku zamykania Oddziałów KGHM Polska Miedź S.A. Obecność strefy przemysłowej zachęci inwestorów, np. firmy z branż wysokich technologii, do umieszczenia na tym obszarze swoich zakładów, co wpłynie na rozwój regionu i uniezależnienie się od monokultury przemysłu miedziowego.

\section{Literatura - References}

1. KGHM Polska Miedź S.A. 2016: KGHM Alfabet, Alphabet, Alfabeto

2. Polska Agencja Przedsiębiorczości Benchmarking parków technologicznych w Polsce. 2008, Wyniki badania, str. 9

3. KGHM Polska Miedź S.A.: Zrównoważony Raport KGHM Polska Miedź S.A. za 2018 rok, str. 9

4. Urząd Gminy Lubin, strona www, http://www.ug.lubin.pl/specjalna-strefa-ekonomiczna-na-blisko-300-hektarach-gminy-lubin/ (stan na 21.01.2020)

5. Urząd Marszałkowski Województwa Dolny Śląsk, strona www, http://www.umwd.dolnyslask.pl/en/urzad-marszalkowski/aktualnosci/single-view/artykul/spotkanie-w-kancelarii-premiera-w-sprawie-lubinskiego-parku-inwestycyjnego/

6. Urząd Marszałkowski Województwa Dolny Śląsk, http://www.umwd.dolnyslask.pl/en/urzad-marszalkowski/aktualnosci/single-view/artykul/spotkanie-w-kancelarii-premiera-w-sprawie-lubinskiego-parku-inwestycyjnego/ (stan na 21.01.2020)

7. wnp.pl, Energetyka, KGHM przystąpił do zgorzeleckiego klastra energii odnawialnej, https://www.wnp.pl/energetyka/kghm-przystapil-do-zgorzeleckiego-klastra-energii-odnawialnej,306162.html (stan na 21.01.2020)

8. Leonardo Energy, Miedź może odegrać kluczową rolę w procesie transformacji energetycznej, https://leonardo-energy.pl/artykuly/miedz-moze-odegrac-kluczowa-role-w-procesie-transformacji-energetycznej/ (stan na 21.01.2020)

9. Leonardo Energy, Innowacyjność i niskoemisyjność dzięki miedzi, https://leonardo-energy.pl/artykuly/innowacyjnosc-i-niskoemisyjnosc-dzieki-miedzi/ (stan na 21.01.2020)

10. Lubin.naszemiasto.pl, Klaster lotniczy w LSSE, https://lubin.naszemiasto.pl/klaster-lotniczy-w-lsse/ar/c3-3404359 (stan na 21.01.2020)

\section{Perspective for the Construction of an Industrial and Technology Park (Economic Zone) for the Inhabitants of the Copper Basin}

The article presents the perspectives for the construction of an industrial and technology park located in the urban and rural commune of Lubin. This area is characterized by a monoculture of the copper industry associated with the largest employer in the region - KGHM Polska Miedź S.A. The mining activities of Polish Copper will be limited in the long term. For this reason, other possibilities of exploiting the region's potential are being sought. It seems that the construction of an industry and technology park is one of the most promising. Local governments, Lower Silesia voivodship, Industrial Development Agency, National Agricultural Support Center, representatives of KGHM and representatives of the Chancellery of the Prime Minister are showing interest in this undertaking.

Keywords: Lubin, industrial and technology park, KGHM, LGOM 